\title{
Photochemistry on the Space Station-Antibody Resistance to Space Conditions after Exposure Outside the International Space Station
}

\author{
Coussot Gaelle ${ }^{1,{ }^{*}}$, Le Postollec Aurelie ${ }^{2}$, Faye Clement ${ }^{3}$, Baque Mickael ${ }^{4}$, \\ Vandenabeele-Trambouze Odile ${ }^{5}$, Incerti Sebastien ${ }^{6}$, Vigier Flavie, Chaput Didier ${ }^{7}$, Cottin Herve 8, 9 , \\ Przybyla Bartos ${ }^{10}$, Berger Thomas ${ }^{10}$, Dobrijevic Michel ${ }^{2}$
}

1 Univ Montpellier, ENSCM, CNRS, IBMM, F-34093 Montpellier 5, France.

2 Univ Bordeaux, CNRS, LAB, Pessac, France.

${ }^{3}$ Colcom, Cap Alpha, Clapiers, France.

${ }^{4}$ German Aerosp Ctr DLR, Inst Planetary Res Management \& Infrastruct, Res Grp Astrobiol Labs, Berlin, Germany.

5 UBO, IUEM UMR 6197, LMEE, Plouzane, France.

6 Univ Bordeaux, UMR 5797, CENBG, Gradignan, France.

${ }^{7}$ Ctr Natl Etud Spatiales, DCT ME EM, Toulouse, France.

8 Univ Paris Est Creteil, UMR 7583, LISA, Creteil, France.

${ }^{9}$ Univ Paris Diderot, Inst Pierre Simon Lapl, Creteil, France.

10 German Aerosp Ctr, Inst Aerosp Med, Cologne, Germany.

*Corresponding author : Gaelle Coussot, email address : gaelle.coussot@umontpellier.fr

\begin{abstract}
:
Antibody-based analytical instruments are under development to detect signatures of life on planetary bodies. Antibodies are molecular recognition reagents able to detect their target at sub-nanomolar concentrations, with high affinity and specificity. Studying antibody binding performances under space conditions is mandatory to convince space agencies of the adequacy of this promising tool for planetary exploration.
\end{abstract}

To complement previous ground-based experiments on antibody resistance to simulated irradiation, we evaluate in this paper the effects of antibody exposure to real space conditions during the EXPOSE-R2 mission outside the International Space Station. The absorbed dose of ionizing radiation recorded during the 588 days of this mission (220 mGy) corresponded to the absorbed dose expected during a mission to Mars. Moreover, samples faced, at the same time as irradiation, thermal cycles, launch constraints, and long-term storage. A model biochip was used in this study with antibodies in freeze-dried form and under two formats: free or covalently grafted to a solid surface.

We found that antibody-binding performances were not significantly affected by cosmic radiation, and more than $40 \%$ of the exposed antibody, independent of its format, was still functional during all this 
experiment. We conclude that antibody-based instruments are well suited for in situ analysis on planetary bodies.

Keywords : Astrobiology, Cosmic rays, Biochip, Antibody, Planetary exploration 
In the context of planetary exploration, the use of miniaturized instruments based on targetbinding reagent with high specificity and binding affinity is clearly relevant. Indeed, such instruments can, in principle, detect unambiguously thousands of different targets from small molecules like amino acids to complex molecules and microorganisms in a single assay. The basic principle can be summarized as follow: the target-binding reagents, like antibodies $(\mathrm{Ab})$, are fixed on a solid surface to specifically capture their target. In direct methods, target interaction with the binding site of $\mathrm{Ab}$ and the use of appropriate reagents generate a visible signal capable of being measured, for instance, by a charge coupled device (CCD) camera. In the field of astrobiology, several Ab-based biochips have been proposed as miniaturized high throughput detection systems, to detect biomarkers, especially organic ones, in the search for extraterrestrial life (Parro et al., 2005; Le Postollec et al., 2007; Parro et al., 2008; Martins et al., 2011; Parro et al., 2011a, Parro et al., 2011b; Sims et al., 2012; McKay et al., 2013; Smith et al., 2014).

However, space is a hazardous environment in particular due to strong irradiation from primary and secondary particles produced by Galactic Cosmic Rays (GCR) and Solar Energetic Particles (SEP), temperature variations and long duration storage (during the cruise phase especially). As a consequence, one main concern relies on the resistance of biochips to these cumulative space conditions. In recent years, studies have been performed to evaluate the resistance of $\mathrm{Ab}$ to specific space conditions, especially regarding the effect of some ionizing particles on $\mathrm{Ab}$ binding performances (Le Postollec et al., 2009a; Le Postollec et al., 2009b; Baqué et al., 2011; de Diego-Castilla et al., 2011; Baqué et al., 2017; Coussot et al., 2017). However, these groundbased simulations were limited due to the use of one single type and energy particle at a time and the experimental characteristics of the beam (high fluxes in a short exposure time, 
unidirectional irradiation). In the space environment, biochips would be exposed to continuous and sporadic fluxes of various particles in a large range of energies and all directions, concomitantly with other parameters inherent to a space mission including thermal variations, vibrations and storage conditions.

To complement ground-based studies, Derveni et al. conducted in 2007 a 12 days mission on the BIOPAN-6 low Earth orbit platform to demonstrate the effects of cumulative irradiations on two antibodies' ability to bind to their respective antigens (Derveni et al., 2012; Derveni et al., 2013). The absorbed dose recorded at the samples position by the dosimeters was 2.4 milligrays (mGy) during the experiment. Both freeze-dried Ab, in free format and absorbed into laser-cut glass fiber pads, were reported as unaffected with regard to their target-binding abilities after their low Earth orbit platform exposure. Analyses were done with conventional indirect enzyme-linked immunosorbent assays (ELISA). However, major loss of Ab activities $(>70 \%)$ was pointed out and explained by the $\mathrm{Ab}$ preparation procedure, in particular the freezedrying step and storage time period. These issues complicated the interpretation of the results. This study highlighted that using $\mathrm{Ab}$ as target-binding reagent necessitates controlling its ability to bind to its target (refers also as its functionality) after each step of the antibody-based device development. Consequently, for biochips, a control is required after the Ab immobilization onto the solid surface (to determine the initial rate of functional $\mathrm{Ab}$ ), but also after washing, freezedrying, storage, and rehydration steps. These controls permit to precisely quantify the number of $\mathrm{Ab}$ that remains functional after the preparation procedure and before undergoing some putative deleterious experiments.

In the frame of the BiOMAS project (Biochip for Organic Matter Analysis in Space), we developed a model biochip, in which a specific $\mathrm{Ab}$ (anti-horseradish peroxidase $\mathrm{Ab}$, quoted anti-HRP Ab hereafter) was used in free format or covalently immobilized onto a solid surface. 
A direct detection method called "Antibody Anti-HorseRadish Peroxidase (A2HRP)" was developed and fulfilled the validation criteria requested by the Food and Drug Administration (FDA) and the European Medicines Agency (EMA) for the validation of bioanalytical methods (Coussot et al., 2018a, Coussot et al., 2018b).This gold standard method permits to evaluate accurately and precisely the number of free or immobilized functional $\mathrm{Ab}$ (interday variation $<12.1 \%$ ). The Lower Limit of Quantification (LLOQ) corresponds to $1.40 \pm 0.18 \%$ of the initial rate of active Ab. The A2HRP method was successfully used in optimizing freeze-drying conditions to better preserve the Ab functionality, notwithstanding its format (Coussot et al., 2018c), and in evaluating the $\mathrm{Ab}$ resistance under various stressful environments (Coussot et al., 2017, Coussot et al., 2018c).

In this work, we first summarize our experiment (see also Vigier et al. 2013), which was part of the Photochemistry on the Space Station (PSS) project (Cottin et al., 2015) and the analytical developments we conducted prior to the final analyses performed on the samples few weeks after their return to Earth (Coussot et al. 2018a, 2018b and 2018c). Both formats, free anti-HRP $\mathrm{Ab}$ and anti-HRP $\mathrm{Ab}$ immobilized onto a surface, have been conditioned into a homemade sample holder unit and installed outside the International Space Station (ISS) on the EXPOSER2 platform. We then present the results on the resistance of our model biochip against a longtime exposure (more than 18 months) to real space conditions. The relevance of antibody-based biochips for space exploration is finally discussed. 


\section{Materials and methods}

\section{II.1 Chemical, reagents and materials}

122

Mouse monoclonal anti-horseradish peroxidase antibodies (anti-HRP Ab) were obtained from MyBioSource (clone number B215M, batches 2F17811 \& 2F15911, USA). Bovine serum albumin (BSA, fraction V, 96-100\% protein, batch SLB38588V), Horseradish peroxidase (HRP, EC 1.11.1.7, batch SLBF8268V, with a purity index of 1.9), Tween ${ }^{\circledR} 20$ (impurities $\leq 3 \%$ in water), o-phenylenediamine dihydrochloride (OPD-2HCl), hydrogen peroxide $\left(\mathrm{H}_{2} \mathrm{O}_{2}\right.$, $30 \%(\mathrm{v} / \mathrm{v})$ solution equivalent to a titer of $120 \mathrm{~V}$ of oxygen $(10.73 \mathrm{M})$ upon opening (Coussot $e t$ al., 2018c)), Dulbecco's Phosphate Buffered Saline (DPBS, 10X solution, pH 7.4, used in a final concentration of $1 \mathrm{X}$ in water solvent), sulfuric acid $\left(\mathrm{H}_{2} \mathrm{SO}_{4}, \geq 97,5 \%\right)$, citric acid ( $\geq$ 99,5\%), sodium hydroxide solution (10M solution for molecular biology), sodium phosphate dibasic dodecahydrate $\left(\mathrm{Na}_{2} \mathrm{HPO}_{4} \cdot 12 \mathrm{H}_{2} \mathrm{O}, \geq 99,0 \%\right)$, sodium bicarbonate $\left(\mathrm{NaHCO}_{3}, \geq 99,5 \%\right)$, sodium carbonate $\left(\mathrm{Na}_{2} \mathrm{CO}_{3}, \geq 99,5 \%\right), \mathrm{D}(+)$-saccharose (sucrose, $\geq 99,0 \%$ ), L-Histidine (His, $\geq 99,0 \%$ ), D-Arginine (Arg, $\geq 99,0 \%$ ), ethanol ( $\mathrm{EtOH}, \geq 99.5 \%$ ), hydrochloric acid ( $\mathrm{HCl}, 37 \%$ ), were purchased from Sigma Aldrich (Saint-Quentin Fallavier, France). Corning DNA Bind ${ }^{\mathrm{TM}}$ 8-well strip plate with N-hydroxysuccinimide modified surface (NHS-wells) were provided by Sigma Aldrich (Saint-Quentin Fallavier, France). NHS-wells were manufactured by Air Liquide (Sassenage, France) to fit perfectly with the shape and size of EXPOSE-R2 closed cells provided by the French Space Agency (CNES, Toulouse) (Vigier et al., 2013), called simply "cells" in the following. These home-designed NHS-wells had a diameter of $8.4 \mathrm{~mm}$ with a 7.1 mm height. Teflon cap were specially manufactured by Air Liquide to close these custom designed NHS-wells (Coussot et al., 2018d). The ultra-pure water was obtained from a Millipore Purification system. Other chemicals are analytical grade and used as received.

During the assays, the relative humidity and air temperature were controlled using a 
thermohygrometer Testo 605-H1 (Type 05600610, identification number 39227197/205), equipment whose calibration is traceable to national standards (certificate number 1306125). During all assays, room temperature was $23.2 \pm 1.3^{\circ} \mathrm{C}$, and recorded relative humidity $(\mathrm{RH})$ was $25.7 \pm 0.9 \%$.

\section{II.2 Sample preparation}

Long-time exposure to real space conditions during the EXPOSE-R2 mission were evaluated on freeze-dried Ab in both covalently immobilized format (labelled "G" for grafted) and insolution $\mathrm{Ab}$ format (free anti-HRP Ab labelled "F" for free). The immobilization strategy, the freeze-drying optimized procedure, the A2HRP validated protocol were detailed elsewhere (Coussot et al., 2017, Coussot et al., 2018a, Coussot et al., 2018b, Coussot et al., 2018c). The freeze-drying stock solution was freshly prepared and was composed of $1.05 \mathrm{~g}$ of citric acid (0.1M), $38.75 \mathrm{mg}$ of His $(5 \mathrm{mM}), 52.5 \mathrm{mg}$ of $\operatorname{Arg}(5 \mathrm{mM})$ in a final volume of $50 \mathrm{~mL}$ of water and adjusted to $\mathrm{pH} 6.5$ with $\mathrm{NaOH}(10 \mathrm{M})$ before adding $10 \mu \mathrm{L}$ of Tween ${ }^{\circledR 2} 2$.

\section{II.2a Preparation of anti-HRP Ab in free format}

The home-designed NHS-wells were filled up with $250 \mu \mathrm{L}$ of BSA (3\% (w/v) in DPBS (1X)). After overnight reaction time at room temperature (RT) in the dark, the wells were emptied and rinsed three times with DPBST solution (DPBS (1X) with $0.05 \%(\mathrm{v} / \mathrm{v})$ Tween $\left.{ }^{\circledR 20}\right)$ and three times with DPBS. An anti-HRP Ab solution was directly prepared at $200 \mu \mathrm{g} \cdot \mathrm{mL}^{-1}$ in the above freeze-drying solution immediately before deposit into the BSA-saturated home-designed NHS-wells (noted also as inactivated BSA wells). In each inactivated BSA well, a volume of $100 \mu \mathrm{L}$ of the anti-HRP $\mathrm{Ab}$ in the freeze-drying solution was mixed with $20 \mu \mathrm{L}$ of a freshly prepared sucrose solution (5g. $\mathrm{L}^{-1}$ in water). The wells were placed within the homemade pre- 
frozen aluminium block designed by our group, and kept frozen by adding liquid nitrogen to follow the optimized freeze-drying procedure (Coussot et al., 2018c) as described in the section II.3.

\section{II. $2 b$ Preparation of anti-HRP Ab in covalently immobilized format}

The home-designed NHS-wells were filled up with a $200 \mu \mathrm{g} \cdot \mathrm{mL}^{-1}$ of anti-HRP Ab solution in DPBS (1X). After a minimum of $4 \mathrm{~h}$ under gentle agitation at RT, a saturation step with $250 \mu \mathrm{L}$ of BSA solution (3\% w/v in DPBS) per well was carried out to prevent non-specific bindings (Baqué et al. 2011), followed by 3 washings with DPBST solution, and 3 washings with PBS. In each covalently immobilized and saturated $\mathrm{Ab}$ wells were added $100 \mu \mathrm{L}$ of the freeze-drying solution and $20 \mu \mathrm{L}$ of a freshly prepared sucrose solution (5g.L $\mathrm{L}^{-1}$ in water). Samples were then freeze-dried using the homemade aluminium holder as described in the section $\boldsymbol{I I . 3}$.

\section{II.3 Freeze-drying procedure}

The aluminium holder had the advantage of running multiple samples at the same time avoiding freeze-drying batch effects. As described elsewhere, this device was pre-frozen and transferred into the central part of a freeze-dryer (Christ Alpha 2-4 from Martin Christ GmbH, Germany) (Coussot et al., 2018c). Freeze-drying was performed overnight (condenser temperature $-85^{\circ} \mathrm{C}$, vacuum 0.05 mbar). When the freeze-drying process was achieved, the chamber of the freezedryer was filled with nitrogen gas before closing the sample-containing aluminium holder, which kept the samples hermetically sealed and sheltered them from the moisture and light until its opening. The opening of the aluminium holder was done in a glove box under a controlled atmosphere of helium $(10 \% \mathrm{He})$ in argon (Ar) provided by Air Liquide (Sassenage, France) to maintain a RH level of $10 \%$ to $15 \%$. During our experiments in the glove box, the RH and air 
temperature were controlled using a thermohygrometer Testo 605-H1 (Testo, France). RH was $12 \pm 3 \%$ and air temperature was $22.8 \pm 2.3^{\circ} \mathrm{C}$. After opening the aluminium holder, freeze-dried samples were capped and directly transferred into the CNES closed cells using a tool vacuum suction pen (FFQ939 from Mayf's Online Shop, China). Into each cell, two ThermoLuminescent Dosimeters (TLDs) were placed at the bottom of the cell, below the samples. These passive dosimeters were analyzed at the end of the mission. The absorbed dose measured into the cells was 220 mGy that corresponds to the dose that can be expected during a mission to Mars including 8 months travel and 18 months at Mars surface. (Hassler et al., 2014; Coussot et al., 2018d). The cells were then screwed with a final tightening of $0.7 \mathrm{Nm}$ using a torque screwdriver TorqueVario ${ }^{\circledR}-\mathrm{S}$ (Wiha, Germany) (Vigier et al., 2013; Coussot et al., 2018d).

\section{II.4 Experiment outside the International Space Station (ISS)}

To study the impact of all constraints encountered by a biochip during an entire space mission (long duration storage, transportation, take-off/landing shocks, thermal constraints, and cumulative effects of cosmic rays particles), 41 anti-HRP Ab samples (21 anti-HRP Ab in the free format "F" and 20 in the covalently immobilized format "G") took part of the "Biochip in PSS experiment" (Vigier et al., 2013; Cottin et al., 2015) during the EXPOSE-R2 mission. An overall view of EXPOSE-R2 mission is illustrated in Figure 1. All samples (14 exposed on ISS and 27 kept on Earth) were simultaneously prepared, within the same freeze-drying batch, as described in the experimental section II.3. The 14 exposed cells were spread on the 2 exposure levels of the Tray 3 of the EXPOSE carrier dedicated to the PSS experiment (4F and 3G antiHRP Ab in each level). Disposition of the exposed cells on the sample carrier was the same for the upper and the lower level of the tray 3 (denoted as upper tray and lower tray, respectively). 
Launch to ISS (July $\left.23^{\text {th }}, 2014\right)$ and storage inside ISS was at ambient temperature $\left(22-25^{\circ} \mathrm{C}\right.$ on average) (Rabbow et al., 2017). Then, the EXPOSE-R2 platform was placed outside the ISS on the Universal platform D on August $18^{\text {th }}$ with opening of the valves for venting the inner part of EXPOSE-R2 on August $20^{\text {th }}$, and removal of the UV shield in October $22^{\text {nd }}, 2014$. On February $3^{\text {rd }}, 2016$ trays were covered and brought back inside the ISS. Thus, the exposed samples spent 566 days outside the ISS over the 588 days of the mission (1 year, 8 months).

During their extravehicular exposition, the samples on Tray 3 were submitted to radiations and temperatures varying between $-20.9^{\circ} \mathrm{C}$ and $57.98^{\circ} \mathrm{C}$ (Rabbow et al., 2017). On March $2^{\text {nd }} 2016$, EXPOSE-R2 Tray 3 landed on Earth. During transit from the Baïkonur cosmodrome to Moscow, and from Moscow to the German Aerospace Center (DLR, Germany) a recording of temperatures was done, the temperatures oscillated between $20^{\circ} \mathrm{C}$ and $24^{\circ} \mathrm{C}$, then from DLR to LISA (Laboratoire Interuniversitaire des Systèmes Atmosphériques, Créteil, France) (Rabbow et al., 2017), and from Créteil to Montpellier a controlled chamber at $4^{\circ} \mathrm{C}$ was used during transportation in the summer period. De-integration of the exposed cells from the sample carriers was done according to MUSC/DLR/ESA/CNES internal procedures (Rabbow et al., 2017). On June $24^{\text {th }} 2016$, the soldered joint of all the cells (including ground references) was removed, using a mechanical lathe and a manufactured CNES tool, in the mechanics department of the Montpellier University (Coussot et al., 2018d). Samples were immediately sealed in a FoodSaver ${ }^{\mathrm{TM}}$ bag (Fischer Scientific, France) and stored in the dark at $4^{\circ} \mathrm{C}$ until analysis with the A2HRP method (section II.7) 
During the same period, experiments were performed on ground to control the long-term behaviour of anti-HRP Ab upon storage but not exposed to space conditions. A total of twentyseven mission ground controls were studied. Six ground cells (3F and $3 \mathrm{G}$ anti-HRP Ab) were stored at the French Space Agency (CNES, Toulouse) by maintaining an accurate temperature control at $3.9^{\circ} \pm 0.8^{\circ} \mathrm{C}$ over that period. Twenty-one ground cells were kept in DLR (Cologne, Germany): six ground cells (3F and $3 \mathrm{G}$ anti-HRP $\mathrm{Ab}$ ) were stored at $5^{\circ} \mathrm{C}$ and eight ground cells (4F and 4G anti-HRP $\mathrm{Ab}$ ) underwent the same thermal history as ISS samples (DLR $\Delta \mathrm{T}$ ), and seven ground samples (4F and $3 \mathrm{G}$ anti-HRP $\mathrm{Ab}$ ) were stored in conditions combining long time storage, varying thermal environment as ISS ones, and UV radiations (DLR $\Delta T+U V$ ) (Rabbow et al., 2017). All of these 27 ground cells were brought back to Montpellier to be analyzed simultaneously with the 14 exposed cells during all the desoldering process and $4^{\circ} \mathrm{C}$ storage before rehydration. For the free format, rehydration was done with $100 \mu \mathrm{L}$ of water and $20 \mu \mathrm{L}$ of carbonate-bicarbonate buffer $(0.1 \mathrm{M}, \mathrm{pH} 9.2)$ per well in order to fix the $\mathrm{pH}$ of the sucrosecontaining freeze drying $\mathrm{Ab}$ solution to 7.4 to preserve $\mathrm{Ab}$ functionality. Free $\mathrm{Ab}$ were then covalently coupled to NHS-wells following the procedure described in section $\boldsymbol{I I . 2 b}$. For the grafted format, rehydration was carried out with $120 \mu \mathrm{L}$ of DPBS. The rate of functional $\mathrm{Ab}$ in both formats was determined with the A2HRP method (section II.7, Figure 1C).

\section{II.6 Additional ground thermal cycling experiments}

The anti-HRP Ab were freeze-dried in both formats as described in section II.3. Thermal cycling experiments were carried out on freeze-dried samples in their sealed bags in a temperature test chamber (Vötsch VT 4004). Two independent thermal variation experiments were done: one with a sharp rise in temperature $\left(5^{\circ} \mathrm{C} / \mathrm{min}\right)$ reaching a one-hour plateau at $80^{\circ} \mathrm{C}$ (referred as " $80^{\circ} \mathrm{C}$ peak" in the text), and a long cycling period (178.8 hours or 7.45 days) mimicking thermal variations of exposed cells (see Coussot et al., 2018d) with an amplitude of 
about $70^{\circ} \mathrm{C}$ (referred as "long cycle" in the text). Samples were rehydrated as described above and analyzed with the A2HRP method.

\section{II.7 Validated A2HRP method and data interpretation}

For all ground-based experiments and that of the overall ISS mission, the A2HRP method

(Figure 1C) was used to evaluate the functionality of anti-HRP Ab towards its antigen HRP. Briefly, the principles are as following: once the anti-HRP Ab were immobilized onto the NHSwells to reach a density of $3.9 \times 10^{11}$ antibody per $\mathrm{mm}^{2}$ (section II.2b)(Moreau et al., 2011), a HRP stock solution $\left(1 \mathrm{~g} . \mathrm{L}^{-1}\right)$ was prepared by dissolving the enzyme in a stabilizing solution composed of $0.1 \mathrm{M} \mathrm{Na}_{2} \mathrm{HPO}_{4}$ and $0.05 \mathrm{M}$ citric acid, $\mathrm{pH}$ 5.2. A HRP working solution at 200 $\mu \mathrm{g} . \mathrm{mL}^{-1}$ was prepared immediately before use from the HRP stock solution by dilution in DPBS. A volume of $110 \mu \mathrm{L}$ of the HRP working solution was pipetted into wells containing the previously grafted anti-HRP antibody to saturate all of its binding sites (Moreau et al., 2011). At least 2 hours at RT or overnight incubations were considered for maximal binding of HRP to anti-HRP Ab surfaces. Unbound HRP was removed by rinsing 3 times with DPBST and 3 more times with DPBS. The wells were then incubated with a freshly prepared $o$ phenylenediamine dihydrochloride/hydrogen peroxide $\left(\mathrm{OPD} / \mathrm{H}_{2} \mathrm{O}_{2}\right)$ solution. The $\mathrm{OPD} / \mathrm{H}_{2} \mathrm{O}_{2}$ reaction solution was composed of $1 \mathrm{~mL}$ OPD stock solution at 5 g.L.-1 in deionized water, 8.6 $\mathrm{mL}$ of stabilizing solution described above, and $400 \mu \mathrm{L}$ of $30 \% \mathrm{H}_{2} \mathrm{O}_{2} .50 \mu \mathrm{L}$ of this $\mathrm{OPD} / \mathrm{H}_{2} \mathrm{O}_{2}$ reaction solution and $50 \mu \mathrm{L}$ of stabilizing solution were mixed into each well. The $\mathrm{HRP} / \mathrm{OPD} / \mathrm{H}_{2} \mathrm{O}_{2}$ reaction that converts OPD to 2,3-diaminophenazine (DAP) was then stopped after 4 min by adding $30 \mu \mathrm{L}$ of STOP solution $\left(\mathrm{H}_{2} \mathrm{SO}_{4}, 4 \mathrm{~N}, \mathrm{pH}<1\right)$. The HRP-catalyzed OPD oxidation into DAP was recorded at $490 \mathrm{~nm}$ with an Infinite $200^{\mathrm{TM}}$ absorbance microplate reader from Tecan (Lyon, France). The activity of the Ab surfaces is expressed as a percentage 
of the sample/reference ratio of its net absorbance values. The net absorbance values correspond

287 to the measured assay values minus the mean absorbance of the blank obtained with inactivated 288 BSA-wells (section $\boldsymbol{I I . 2 a})$.

289 All data were reported as the mean \pm the standard deviation (SD) from at least three replicate 290 experiments. Statistical significance of the assays was determined using Student's $t$ test $291(p=0.05)$. 
Stress affects $\mathrm{Ab}$ performances in different ways depending on the type and duration of the event (Coussot et al., 2018b; Coussot et al., 2018c). Irradiation effects on anti-HRP Ab was assessed here by evaluating the functionality of the anti-HRP Ab before and after the stress event or by comparing the activity of exposed $\mathrm{Ab}$ samples to that of non-exposed ones (named ground references (GR) or controls, see above). Analyses were done according to the validated A2HRP method (Figure 1C). The A2HRP method was demonstrated to have the potential for analyzing the binding ability of the anti-HRP $\mathrm{Ab}$ in both formats even if deleterious events occurred on the anti-HRP Ab before its coupling to the surface (Coussot et al., 2018c). This direct assay permits a precise and reliable quantitation of HRP bound on the immobilized Ab surface, and consequently to evaluate the anti-HRP $\mathrm{Ab}$ binding capacities. It has also demonstrated its suitability to evaluate discrepancies in Ab bindings after their exposure to we evaluate the $\mathrm{Ab}$ resistance after their exposure to real space conditions, and thus for the first time the effect of cumulative and long-term stress events on the performance of a grafted $\mathrm{Ab}$. In order to broadly represent any future Ab-based biochip instruments, we evaluated in a second part, free $\mathrm{Ab}$ format since both free and grafted $\mathrm{Ab}$ are considered for future applications in planetary exploration. III.1. Resistance of anti-HRP Ab in its grafted format after exposure outside the ISS Since radiation gradients were observed on the EXPOSE platform in previous ISS missions (Berger et al., 2012), the 14 exposed Ab "Flight samples" were spread on the 2 exposure levels of the Tray 3 of the EXPOSE carrier dedicated to the PSS experiment, but with the same 
disposition on the upper and the lower level of the carrier. All the experiments performed on grafted $\mathrm{Ab}$ are reported in Figure 2. To only take into account the effects encountered during the ISS mission (flights, extravehicular exposure, and all transportations during the mission), the percentage of functional $\mathrm{Ab}$ is calculated using the freeze-dried ground samples stored at $5^{\circ} \mathrm{C}$ in DLR facility ( $n=2$ replicates) during all the duration of the mission. At first view, the results reveal a possible degradation of several samples including flight samples. Higher variability in the estimated recognition capabilities of our $\mathrm{Ab}$ has been observed when using custom designed NHS-wells with a within-assay precision equals of $10.3 \%$ for that custom designed wells batch, in comparison with conventional ones (within-assay precision is less than 7.1\%; Coussot et al., 2018b). The effects of transportation are evaluated by confronting activity of ground controls stored in DLR with that of CNES ground samples. Remaining activity of both CNES and DLR grounds controls, are not statistically different (Student's $t$-test). No significant effect is also observed with the ground sample named DLR $\Delta T+U V$, which combines long time storage, varying thermal environment mimicking ISS ones, and UV radiations. To complement these data, we run here additional ground thermal cycling the anti-HRP $\mathrm{Ab}$ over a $80^{\circ} \mathrm{C}$ short peak of temperature, a long cycle mimicking thermal variations of flight samples (see section II.6 of the experimental part), and compared with an identical storage time at $4^{\circ} \mathrm{C}$. All assays were performed with eight replicates. Ab activities are presented in Figure 3. A degradation of $1 / 3$ of initially active grafted $\mathrm{Ab}$ (corresponding to $66 \%$ of surface active $\mathrm{Ab}$ ) is shown during the freeze-drying process by comparing data obtained with fresh $\mathrm{G} \mathrm{Ab}$ that did not undergo freeze-drying with that of rehydrated sample upon opening of the aluminium holder (Figure 3, first two shaded bars with grey lines). In addition, comparing results from the overall process, cumulating the freeze-drying step and 
storage, shaded grey bars indicate a slight but significant difference in activity between the three stored freeze-dried samples $\left(55.1 \pm 4.1\right.$ for the $4^{\circ} \mathrm{C}$ storage; $48.5 \pm 3.2$ for the $80^{\circ} \mathrm{C}$ peak; $46.7 \pm 4.1$ during the long cycle) and the freeze-dried sample analysed with no storage $(66.8 \pm 6.7)$ whereas the percent $\mathrm{Ab}$ activity values after the sole freeze-drying process are $83.1 \pm 14.5,69.8 \pm 13.1$, and $72.5 \pm 12.1$ for the freeze dried $4^{\circ} \mathrm{C}$ storage, the $80^{\circ} \mathrm{C}$ peak, and long cycle, respectively, indicating that there were not significant differences $(p>0.05)$ between the reference sample with no storage and the 3 stored ones (Figure 3, filled grey bars).

\section{III.2. Resistance of anti-HRP Ab in free format after exposure outside the ISS}

Since a $30 \%$ functional activity difference in freeze-dried $\mathrm{Ab}$, between the free format and the covalently immobilized one, has been reported in literature depending on the freeze-drying formulation components (Coussot et al., 2018c), and that only free Ab format has been studied in previous experiments on the BIOPAN-6 low Earth orbit platform (Derveni et al., 2012; Derveni et al., 2013), the resistance of free anti-HRP Ab after exposure to real space conditions is detailed hereafter.

Previous data using the same freeze-drying solution adjusted to $\mathrm{pH} 7.4$ for $\mathrm{Ab}$ immobilization to the NHS-wells showed that free Ab activity losses under $25 \pm 2 \%$ could not be quantified with the A2HRP method due to sample preparation, multi-step procedure, and handlings (Coussot et al., 2018c). However, the A2HRP method has the advantage of providing reliable and precise data for stability studies of the free anti-HRP $\mathrm{Ab}$, by comparing with conventional competitive inhibition assays. Indeed, changes in Ab properties upon degrading conditions were proved to dramatically affect the data in conventional immunoassays with high variability of the results. It is also restricted to competitive mechanism of inhibition; if other mechanisms occurred at the same time in the sample it would generate uninterpretable data. All the results from the 
EXPOSE-R2 mission samples illustrated in Figure 4, were obtained with the A2HRP method. No significant alteration of the free anti-HRP $\mathrm{Ab}$ is observed after both $80^{\circ} \mathrm{C}$ peak and long cycle exposures (data from ground experiments not shown). As shown by Coussot et al. 2018c, a possible additional air moisture degrading effect might have occurred during the storage of the freeze-dried $\mathrm{F}$ anti-HRP $\mathrm{Ab}$ at $4^{\circ} \mathrm{C}$ (sealed bag not perfectly hermetic). Owing to the inherent conditions of the rehydration step, this result is not surprising and correlates well with the above observations on the freeze-dried $G A b$, and that of free GR stored in DLR (73.7 $\pm 10.3 \%)$. Consequently, considering all the results presented in Figure 4, no significant differences $(p>0.05)$ are observed in the binding activity of the anti-HRP Ab, under its free format, with the same order of activity for the flight samples as for the ground ones. As before, a $37 \%$ drop in remaining free $\mathrm{Ab}$ activity is necessary to detect alterations in $\mathrm{Ab}$ binding efficiency from cosmic radiations during flight samples exposure outside the ISS.

\section{Discussion}

In this study, we evaluated the effect due to a long-term exposure to temperature variations on the activity of anti-HRP Ab in its grafted format but independently from flight samples (Figure 3). Indeed, the effect of short exposure of covalently grafted $\mathrm{Ab}$ at elevated temperatures was previously published (Coussot et al., 2018c). It revealed that about $60 \%$ of the initial activity of covalently immobilized $\mathrm{Ab}$ was preserved during short temperature stress. We reported also that freeze-dried samples suffered less from stress due to temperature exposure than from the rehydration step, probably due to changes in composition of the solid form upon contact with air moisture, which was supposed to lead to only a partial refolding of the freeze-dried Ab. Thus, after exposure of grafted Ab to thermal variations, activity changes, if they occurred, might not be due to an effect of temperature but rather from storage time. Indeed, the results of 
remaining $\mathrm{Ab}$ activity after the freeze-drying process show no discrepancy $(p>0.05)$ between the reference sample with no storage and the 3 stored ones (Figure 3, filled grey bars). This means that an alteration of $\mathrm{Ab}$ bindings other than those occurring during the freeze-drying process/rehydration or thermal variations might be evoked only if there is more than $40 \%$ drop in remaining $\mathrm{Ab}$ activity (from freeze-dried control) after a long-duration experiment. This is consistent with tests done on GR samples illustrated in Figure 2.

Measurements performed with passive dosimeters during the EXPOSE-R2 mission revealed, a posteriori, that the absorbed dose difference between cells at upper and lower levels was low (about $3 \mathrm{mGy}$ for the whole mission corresponding to $1.4 \%$ of the total). We explained this difference due to an estimated shielding of TLDs of $0,82 \mathrm{~g} / \mathrm{cm}^{2}$ on the upper level (Coussot et al., 2018d) so the absorbed dose remains quasi uniform between the two levels. This can explain why the results we obtained for the "upper tray" and the "lower tray" samples have no statistical differences. Indeed, we obtained a remaining activity of $50.6 \pm 9.0 \%$ for the flight "upper tray" samples, and $62.9 \pm 11.0 \%$ for the flight "lower tray" for grafted Ab (Figure 2). For free format, our results showed that a $37 \%$ drop in remaining free $\mathrm{Ab}$ activity is necessary to detect alterations in $\mathrm{Ab}$ binding efficiency. In other words, this shows that much more than $63 \%$ of the free anti-HRP $\mathrm{Ab}$ are still functional after their long-duration exposure outside the ISS (Figure 4). Consequently, based on all the above considerations, our results show that grafted and free $\mathrm{Ab}$ partially keep their recognition capabilities during the overall flight mission, and that the degradations from cosmic radiations, if any, are too small to be detected by our analysis protocols.

Nevertheless, due to the high number of potentially hazardous factors encountered during a space mission (McKenna-Lawlor et al., 2012), our experiment demonstrates with confidence, 
413 for the first time, that much more than $40 \%$ of $\mathrm{Ab}$ (whatever the format) survived to the longduration exposure outside the ISS and remained functional.

Antibody-based biochips have not been used yet for planetary exploration missions although their high potential for searching tracers of extinct or extant life (Parro et al. 2011c). One major concern for an instrument based on this technology is radiation effect issues on the antibodies. Many laboratory experiments have been performed so far at different energies with different particles and high fluences (much more important than suspected for a mission to Mars for instance) to test the ability of antibodies to recognize their target after radiation exposure (Le Postollec et al., 2009a; Le Postollec et al., 2009b; Baqué et al., 2011; de Diego et al., 2011; Baqué et al., 2017; Coussot et al., 2017). A 12 days mission on the BIOPAN-6 low-earth orbit platform has been performed to study the effects of cumulative irradiations on two antibodies' ability to bind to their respective antigens (Derveni et al., 2012; Derveni et al., 2013). In the present paper, we improved previous studies to better test the effects of real-space constraints on antibodies during an EXPOSE-R2 mission outside the International Space Station. In terms of radiation, the total accumulated radiation dose recorded by the dosimeters during the EXPOSE-R2 is $220 \mathrm{mGy}$, which is much higher than those measured during the BIOPAN-6 low Earth orbit experiment (2.4 mGy) (Derveni et al., 2012), and is in agreement with the absorbed dose expected during a mission to Mars (Hassler et al. 2014, Le Postollec et al. 2009a). All these studies show two major results: (1) the preparation procedure and analytical steps have to be controlled and validated with care to obtain reliable results. (2) no clear deleterious effect have been reported so far on the antibody and antigen recognition step, in the limit of detection of the analysis protocols. 
As a consequence, to our opinion, radiation effects on the antibodies should not been considered anymore as an issue for antibody-based instruments dedicated to a planetary mission (in particular for the exploration of Mars).

\section{Conclusions}

The aim of our study was to test whether space flight conditions might have influences on the performances of Ab-based biochips. A direct, precise and reliable assay was used to evaluate the remaining activity of ground controls and flight samples that underwent long-term storage, temperature variations, and shocks all along the EXPOSE-R2 mission. The results presented in this paper show that cosmic radiation has no significant effect on the antibody recognition ability, independent of the exposed format, free or immobilized onto a solid surface. These results are in agreement with all the previous ground-based experiments performed on irradiation facilities with different particles at various energies.

In that experiment, since we precisely managed all the steps of the analytical protocol and of the sample conditioning under controlled atmosphere, and with all the necessary steps to consider during the overall mission (Figure 1), we clearly demonstrated the relevance and adequacy of antibody based instruments to be used for future planetary exploration experiments. 
457 The authors would like to thank the French national space agency (CNES) for financial support 458 (05/2182/00-DCT094). The authors thank Jean-Louis Kergueme from the Mechanics 459 Department of the Montpellier University for his assistance during the desoldering of the cells, 460 and Drs. Sonia Khier \& Yann Ladner for their assistance that has led to good progress during 461 the analysis of samples. 
464

465

466

467

468

469

470

471

472

473

474

475

476

477

478

479

480

481

482

483

484

485

486

487

488

489

490

491

492

493

494

495

496

497

498

499

500

501

502

503

Baqué, M., Le Postollec, A., Coussot, G., Moreau, T., Desvignes, I., Incerti, S., Moretto, P., Dobrijevic, M., Vandenabeele-Trambouze, O. (2011a) Biochip for astrobiological applications: Investigation of low energy protons effects on antibody performances. Planetary and Space Science 59(13):1490 - 1497.

Baqué, M., Dobrijevic, M., Le Postollec, A., Moreau, T., Faye, C., Vigier, F., Incerti, S., Coussot, G., Caron, J., Vandenabeele-Trambouze, O. (2017) Irradiation effects on antibody performance in the frame of biochip-based instruments development for space exploration. International Journal of Astrobiology 16(1): 82-90.

Berger, T., Hajek, M., Bilski, P., Koerner, C., Vanhavere, F., Reitz, G. (2012). Cosmic radiation exposure of biological test systems during the EXPOSE-E mission. Astrobiology 12(5): 387-392.

Cottin, H., Saiagh, K., Nguyen, D., Grand, N., Benilan, Y., Cloix, M., Coll, P., Gazeau, M-C., Fray, N., Khalaf, D., Raulin, F., Stalport, F., Carrasco, N., Szopa, C., Chaput, D., Bertrand, M., Westall, F., Mattioda, A., Quinn, R., Ricco, A., Santos, O., Baratta, G., Strazzulla, G., Palumbo, M.E., Le Postollec, A., Dobrijevic, M., Coussot, G., Vigier, F., VandenabeeleTrambouze, O., Incerti, S., Berger, T. (2015) Photochemical studies in low Earth orbit for organic compounds related to small bodies, Titan and Mars. Current and future facilities, Bulletin de la Société Royale des Sciences de Liège 84 : 60-73.

Coussot, G., Moreau, T., Faye, C., Vigier, F., Baqué, M., Le Postollec, A., Incerti, S., Dobrijevic, M., Vandenabeele-Trambouze, O. (2017) Biochip-based instruments development for space exploration: influence of the antibody immobilization process on the biochip resistance to freeze-drying, temperature shifts and cosmic radiations. International Journal of Astrobiology 16(2):190-199.

Coussot, G., Faye, C., Le Postollec, A., Dobrijevic, M. (2018a) One-step direct immunoassay with horseradish peroxidase as antigen for studying the functionality of antibody surfaces. Talanta, 178:922-927.

Coussot, G., Faye, C., Le Postollec, A., Dobrijevic, M. (2018b) A gold standard method for the evaluation of antibody-based materials functionality: Approach to forced degradation studies. Journal of Pharmaceutical and Biomedical Analysis, 152:17-24.

Coussot, G., Faye, C., Le Postollec, A., Dobrijevic, M. (2018c) A methodological approach for the thermal stability and stress exposure studies of a model antibody. Analytical Biochemistry, 548: 23-31. 
Coussot, G., Le Postollec, A., Incerti, S., Baqué, M., Faye, C., Vandenabeele-Trambouze, O., Cottin, H., Ravelet, C., Peyrin, E., Fiore, E., Vigier, F., Caron, J., Chaput, D., Przybyla, B. Berger, T., Dobrijevic, M. (2018d) Photochemistry on the Space Station - Aptamer resistance to space constraints: particles exposure from irradiation facilities and real exposure outside the International Space Station. Astrobiology, submitted in April 2018.

de Diego-Castilla, G., Cruz-Gil, P., Mateo-Martí, E., Fernández-Calvo, P., Rivas, L.A., Parro, V. (2011) Assessing antibody microarrays for space missions: effect of long-term storage, gamma radiation, and temperature shifts on printed and fluorescently labeled antibodies. Astrobiology 11(8):759-773.

Derveni, M., Allen, M., Sawakuchi, G.O., Yukihara, E.G., Richter, L., Sims, M.R., Cullen, D.C. (2013) Survivability of immunoassay reagents exposed to the space radiation environment on board the ESA BIOPAN-6 Platform as a prelude to performing immunoassays on Mars. Astrobiology 13(1):93-102.

Derveni, M., Hands, A., Allen, M., Sims, M.R., \& Cullen, D.C. (2012) Effects of simulated space radiation on immunoassay components for Life-detection experiments in planetary exploration missions. Astrobiology 12(8): 718-729.

Hassler, D M., Zeitlin, C., Wimmer-Schweingruber, R F.; Ehresmann, B.; Rafkin, S.; Eigenbrode, J L.; Brinza, D E.; Weigle, G.; Böttcher, S.; Böhm, E.; and 438 coauthors (2014) Mars' Surface Radiation Environment Measured with the Mars Science Laboratory's Curiosity Rover. Science 343 (6169), id. 1244797.

Le Postollec, A., Dobrijevic, M., Incerti, S., Moretto, P., Seznec, H., Desorgher, L., Santin, G., Nieminen, P., Dartnell, L., Vandenabeele-Trambouze, O., Coussot, G. (2007)

Development of a Biochip dedicated to planetary exploration. First step: resistance studies to space conditions. Journées Semaine de 1'Astrophysique Française 2007.

Le Postollec, A., Incerti, S., Dobrijevic, M., Desorgher, L., Santin, G., Moretto, P., Vandenabeele-Trambouze, O., Coussot, G., Dartnell, L., Nieminen, P. (2009a) Monte Carlo simulation of the radiation environment encountered by a biochip during a space mission to Mars. Astrobiology 9(3): 311-323.

Le Postollec, A., Coussot, G., Baqué, M., Incerti, S., Desvignes, I., Moretto, P., Dobrijevic, M., Vandenabeele-Trambouze, O. (2009b) Investigation of Neutron Radiation Effects on Polyclonal Antibodies (IgG) and Fluorescein Dye for Astrobiological Applications. Astrobiology 9(7): 637-645.

Moreau, T., Faye, C., Baqué, M., Desvignes, I., Coussot, G., Pascal, R., VandenabeeleTrambouze, O. (2011) Antibody-based surfaces: rapid characterization using two complementary colorimetric assays. Analytica Chimica Acta 706: 354-360. 
Martins, Z. (2011) In situ biomarkers and the Life Marker Chip. Astronomy \& Geophysics $52(1): 1.34-1.35$.

McKay, C.P.,Stoker, C.R., Glass, B.J., Davé, A., Davila, A.F., Heldmann, J.L., Marinova, M.M., Fairen, A.G., Quinn, R.C., Zacny, K.A., Paulsen, G., Smith, P.H., Parro, V., Andersen, D.T., Hecht, M.H., Lacelle, D., Pollard, W.H. (2013) The Icebreaker Life Mission to Mars: A Search for Biomolecular Evidence for Life. Astrobiology 13(4): 334-353.

McKenna-Lawlor, S., Gonçalves, P., Keating, A., Reitz, G., Matthiä, D. (2012) Overview of energetic particle hazards during prospective manned missions to Mars. Planetary and Space Science 63-64(0): 123-132.

Parro, V., Rodriguez-Manfredi, J.A., Briones, C., Compostizo, C., Herrero, P.L., Vezb, E., Sebastián , E., Moreno-Paz, M., García-Villadangos, M., Fernández-Calvo, P., GonzálezToril, E., Pérez-Mercader, J., Fernández-Remolar, D., Gómez-Elvira, J. (2005) Istrument development to search for biomarkers on mars: Terrestrial acidophile, iron-powered chemolithoautotrophic communities as model systems. Planetary and Space Science 53(7):729-737.

Parro, V., Fernández-Remolar, D., Rodríguez-Manfredi, J.A., Cruz-Gil, P., Gómez-Elvira, J. (2008) SOLID2: an antibody array-based Life-detector instrument in a Mars drilling simulation experiment (MARTE). Astrobiology 8(5): 987-999.

Parro, V., Fernández-Remolar, D., Rodríguez-Manfredi, J.A., Cruz-Gil, P., Rivas, L.A., RuizBermejo, M., Moreno-Paz, M., García-Villadangos, M., Gómez-Ortiz, D., Blanco-López, Y., Menor-Salván, C., Prieto-Ballesteros, O., Gómez-Elvira, J. (2011a) Classification of modern and Old Rio Tinto sedimentary deposits through the biomolecular record using a Life Marker Biochip: Implications for detecting life on Mars. Astrobiology 11(1): 29-44.

Parro, V., de Diego-Castilla, G., Rodríguez-Manfredi, J.A., Rivas, L.A., Blanco-López, Y., Sebastián, E., Romeral, J., Compostizo, C., Herrero, P.L., García-Marín, A., Moreno-Paz, M., García-Villadangos, M., Cruz-Gil, P., Peinado, V., Martín-Soler, J., Pérez-Mercader, J., Gómez-Elvira, J. (2011b) SOLID3: a multiplex antibody microarray-based optical sensor instrument for in situ Life detection in planetary exploration. Astrobiology 11(1): 15-28.

Parro, V., de Diego-Castilla, G., Moreno-Paz, M., Blanco, Y., Rodríguez-Manfredi, J.A. , Fernández-Remolar, D., Gómez, F., Gómez, M.J., Rivas, L.A., Demergasso, C., Echeverría, A., Urtuvia, V.N., Ruiz-Bermejo, M., García-Villadangos, M., Postigo, M., Sánchez-Román, M., Chong-Díaz, G., Gómez-Elvira, J. (2011c) A microbial oasis in the hypersaline Atacama subsurface discovered by a Life Detector Chip: Implications for the search for Life on Mars. Astrobiology 11(10): 969-996. 
589 Rabbow, E., Rettberg, P., Parpart, A., Panitz, C., Schulte, W., Molter, F.,Willnecker, R.

590 (2017). EXPOSE-R2: The Astrobiological ESA Mission on Board of the International Space

591 Station. Frontiers in Microbiology, 8, 1533. http://doi.org/10.3389/fmicb.2017.01533.

592

593 Sims, M.R., Pullan, D., Holt, J., Blake, O., Sykes, J., Samara-Ratna, P., Canali, M., Cullen,

594 D.C., Rix, C.S., Buckley, A., Derveni, M., Evans, D., Miguel García-Con, L., Rhodes, A.,

595 Rato, C.C., Stefinovic, M., Sephton, M.A., Court, R.W., Bulloch, C., Kitchingman, I., Ali, Z.,

596 Borst, G., Leeuwis, H., Prak, A., Norfini, A., Geraci, E., Tavanti, M., Brucato, J., Holm, N.

597 (2012) Development status of the life marker chip instrument for ExoMars. Planetary and

$598 \quad$ Space Science 72(1): 129-137.

599

600 Smith, H., Parro, V. (2014) Planetary Protection Plan for an Antibody based instrument

601 proposed for Mars2020. in 40 ${ }^{\text {th }}$ COSPAR Scientific Assembly. p. 3140.

602

603 Vigier, F., Le Postollec, A., Coussot, G., Chaput, D., Cottin, H., Berger, T., Triqueneaux, S., 604 Dobrijevic, M., Vandenabeele-Trambouze, O. (2013) Preparation of the Biochip experiment 605 on the EXPOSE-R2 mission outside the International Space Station. Advances in Space 606 Research 52(12): 2168-2179.

607

608 
610 FIG.1. An overall view of the EXPOSE-R2 mission with two formats of freeze-dried anti-HRP antibody $(\mathrm{Ab})$ : first is grafted format $(\mathrm{G})$ with $\mathrm{Ab}$ covalently immobilized on the well-surface and second is free format $(\mathrm{F})$ with $\mathrm{Ab}$ prepared in-solution.

1A) Pre-flight samples preparation with 1) Freeze-drying procedure, conditioning and screwing of the CNES cells under controlled atmosphere, in Montpellier; 2) Soldering of the CNES cells, integration of CNES cells into the trays, in Paris. Ground references (GR) were stored in CNES (Toulouse) and in DLR (Germany); 3) 56P launch from the cosmodrome in Baikonur, 617 Kazakhstan.

1B) EXPOSE-R2 flight with 4) Integration of the trays into the EXPOSE-R monoblock, 26 days stay inside ISS; 5) EVA-39, exposition outside the ISS; 6) EVA-40, removal of the sun shield; 7) EVA-42, end of exposure, return into the ISS and de-integration of the trays; 8) Return to ground, expedition 46 landing, 44S Soyuz capsule.

1C) Post-flight experiments with 9) Disassembly of the PSS carriers, and de-integration of the exposed cells. Ground references (21 GR in DLR and 6 GR in CNES that represent 14F + 13G) brought back to Montpellier; 10) Desoldering of the cells in Montpellier; 11) Analysis of freeze dried samples according to A2HRP method. 1D) A2HRP method principle. A decrease in the HRP-Ab binding events results in a decrease of the absorbance signal (see experimental part for details).

FIG.2. Binding activity of the grafted anti-HRP Ab obtained for ground controls (number of replicates: CNES $n=3$; DLR $n=2$; DLR $\Delta \mathrm{T} n=4$; DLR $\Delta \mathrm{T}+\mathrm{UV} n=3)$ and flight samples $(n=3$ replicates for both lower and upper tray) by the A2HRP method. Each filled grey bar represents the mean and standard deviation (SD) of the Ab activity (normalized value in \%, calculated against freeze-dried ground controls stored in DLR at $5^{\circ} \mathrm{C}(n=2$ replicates $\left.)\right)$.

FIG.3. Binding activity of the grafted anti-HRP $\mathrm{Ab}(\mathrm{G} \mathrm{Ab})$ obtained without and after freezedrying, without storage (instantaneous rehydration after freeze-drying), with storage at $4^{\circ} \mathrm{C}$ for freeze-dried control, with sharp rise in temperature $\left(80^{\circ} \mathrm{C}\right.$ peak), and a thermal cycling experiment mimicking thermal cells exposure outside the ISS (long cycle $\Delta \mathrm{T}$ ) but in accelerated time: one hour of EXPOSE-R2 mission was converted into one minute to carry out this experiment in the lab with similar temperature amplitude (for details see Coussot et al., 2018d). Each bar represents the mean and standard deviation (SD) of the Ab activity ( $n=8$ replicates, normalized value in \%), calculated against freshly prepared Ab surface (shaded bars with grey lines) to evaluate cumulative effects or calculated against freeze-dried $\mathrm{Ab}$ without storage (filled grey bars) to evaluate the effects of storage and temperature.

643 FIG.4. Binding activity of the free anti-HRP Ab obtained for ground controls (number of replicates: CNES $n=3$; DLR $n=3$; DLR $\Delta \mathrm{T} n=4$; DLR $\Delta \mathrm{T}+\mathrm{UV} n=4)$ and flight samples $(n=3$ replicates for both lower and upper tray) by the A2HRP method. Each dark bar represents the mean and standard deviation (SD) of the activity (normalized value in \%, calculated against a freshly prepared freeze-dried ground reference). 


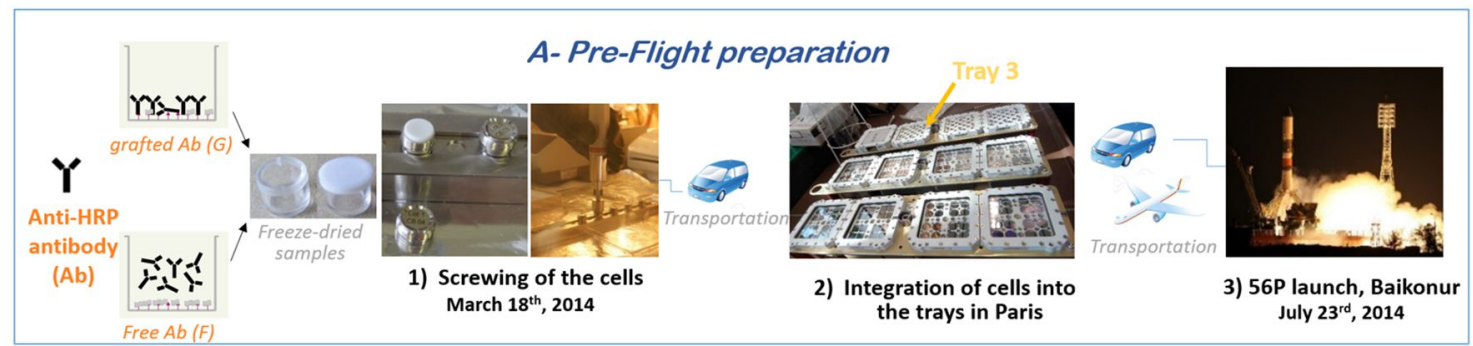

\section{B- Flight Experiment}

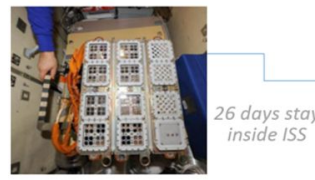

4) Integration of the trays into the EXPOSE-R monoblock August $6^{\text {th }}, 2014$

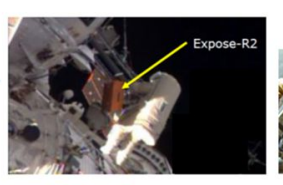

5) Exposition outside ISS EVA-39 ugust $18^{\text {th }}, 2014$

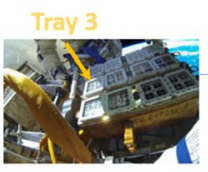

6) Removal of the sunshield, EVA-40 October $2^{\text {th }}, 2014$
7) End of exposure, EVA-42 February $3^{\text {rd }}, 2016$

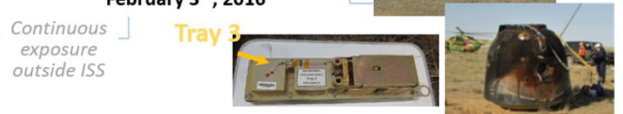

8) Return to ground, Expedition 46 landing

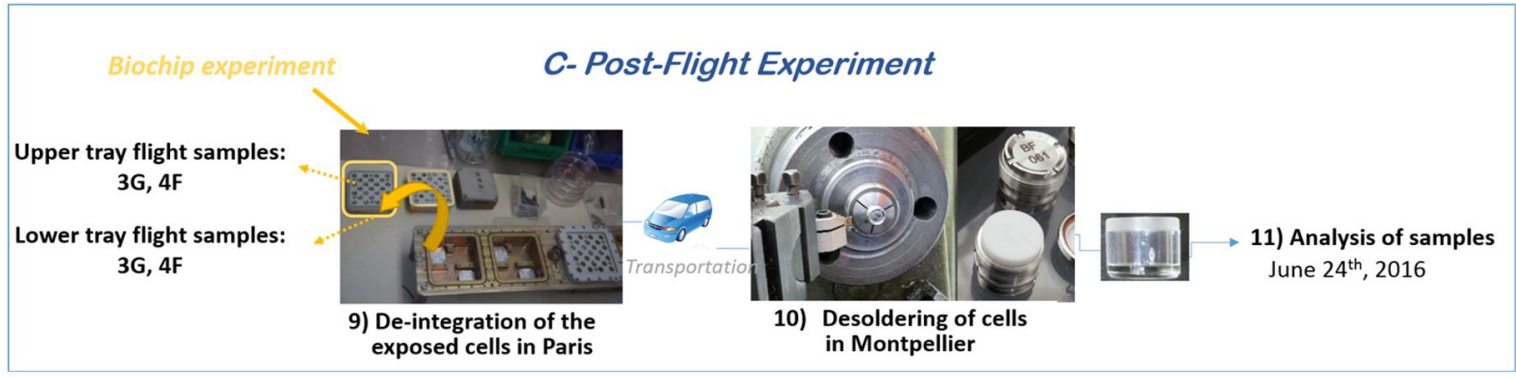

\section{D-A2HRP method}

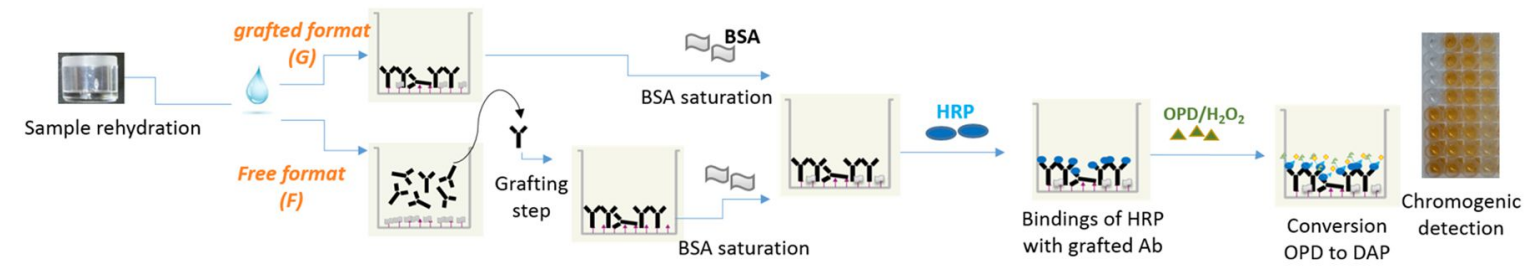




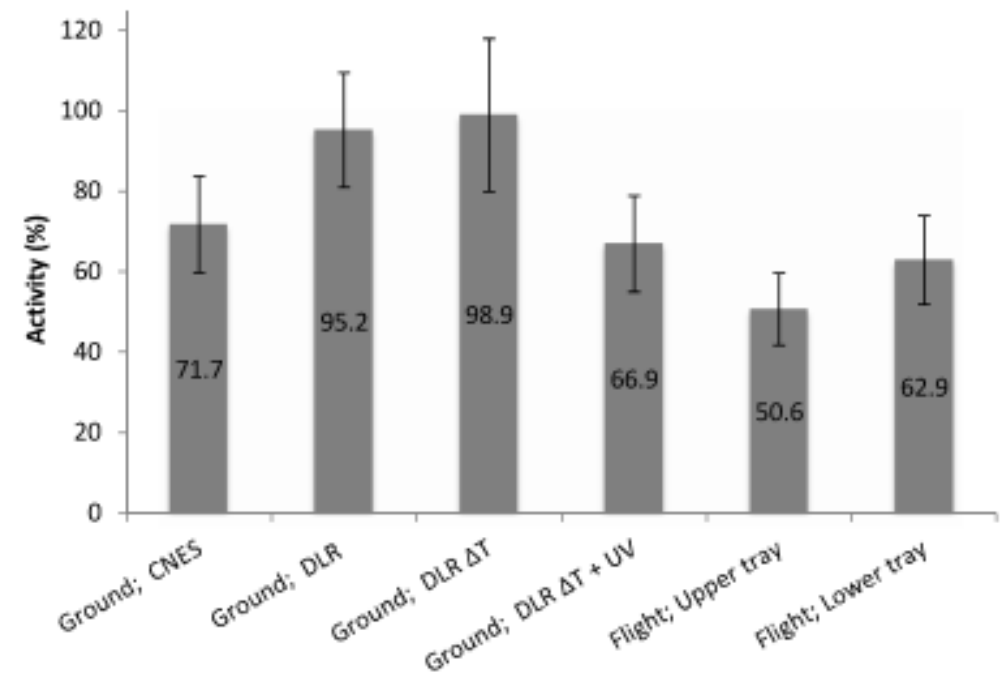

654

FIG.3.

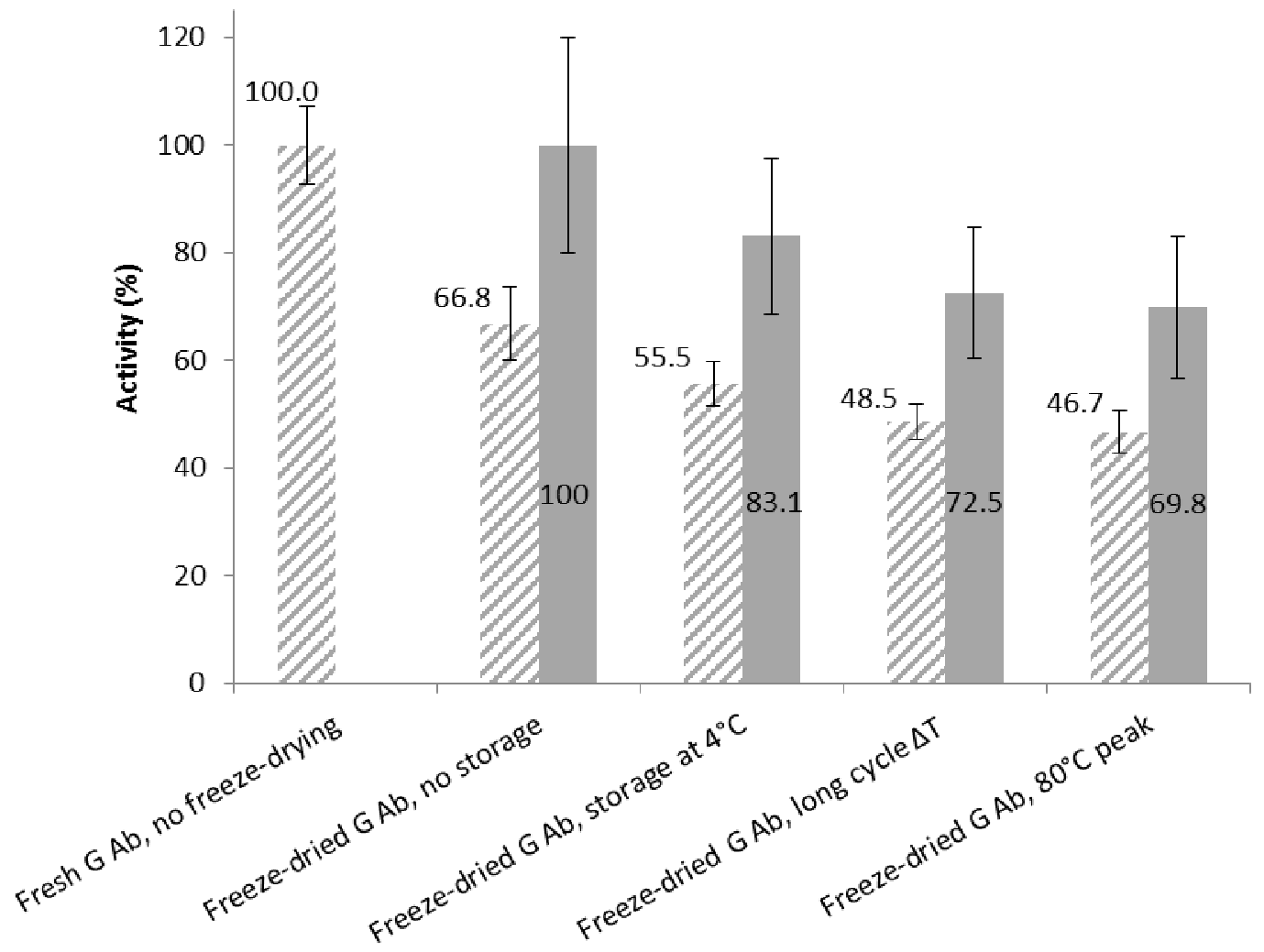

656 


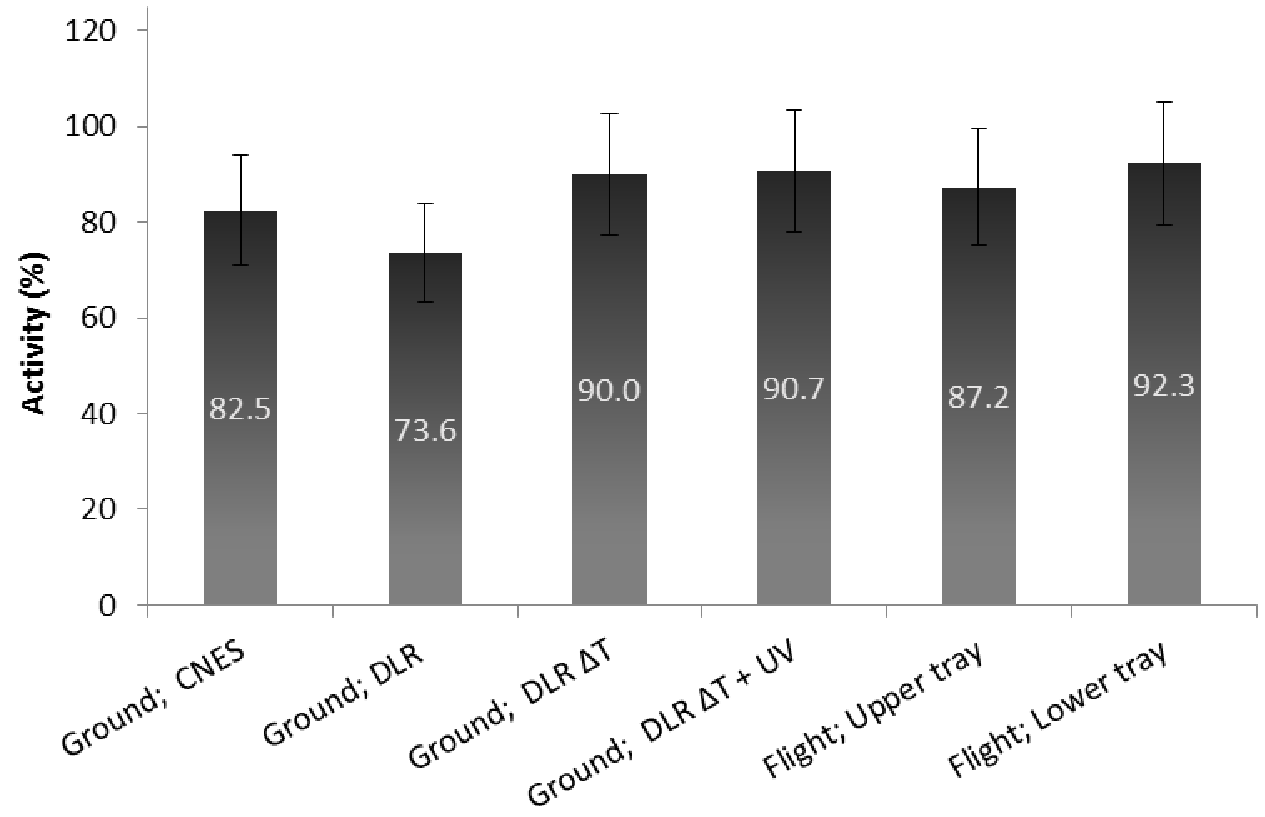

661

662

663 